\title{
A NOTE ON THE THEORY OF INVESTMENT
}

\section{OF THE FIRM}

Friedrich and Vera Lutz's recent book on The Theory of Investment of the Firm $\mathbf{x}$ is an attempt, and within its self-imposed limits a highly successful attempt, to apply the marginal analysis - that is, the theory of profit maximization - to the problem of the time and capital dimensions of the behavior of the firm. It has long been regarded as a weakness of the conventional marginal analysis that it neglects the capital and time structure of the firm, and bases its conclusions on the assumed maximization of a supposedly continuous flow of net revenue. Dr. and Mrs. Lutz have made a determined effort to overcome this defect, by applying the theory of maximization to the variables of the firm as they are spread out in time. There is nothing particularly new in this approach-it has been foreshadowed by Wicksell, Böhm-Bawerk, and developed in modern economics by Hicks, Hart, and many others. In this book however it has been carried to a degree of completeness which leaves the impression that there is practically nowhere else to go on this particular road. As an exercise in the marginal analysis this work might properly claim to be exhaustive, and if the reader occasionally finds it exhausting, he can at least thank the authors for having pursued one road of inquiry practically to the end.

After a brief glance at the nature of time relationships in a productive process the authors proceed to a very thorough discussion, in chapter II, of four possible criteria of profit maximization. It is a little astonishing that at this late date in the development of the theory of maximization it is not wholly clear exactly what is to be maximized. The four criteria discussed are (i) the present value of future net receipts, discounted at market rates of interest; (ii) the ratio of discounted receipts to discounted costs; (iii) the internal rate of return; (iv) the rate of return on the entrepreneur's own capital. The second can be dismissed as having merely historical significance. The fourth is apparently regarded as the true criterion, with which the first almost always coincides. The third coincides with the others only in the highly special case of perfect capital markets and a no-rent enterprise where the internal rate of return and the market rate of interest are identical. The remainder of the work is largely an exercise in the development of the consequences of maximizing discounted net receipts in a great variety of circumstances, plus some tantalizingly brief comments or some broader themes, such as the acceleration principle (on which the analysis casts considerable doubt), the so-called " $\mathrm{Ri}$ cardo effect" of a general rise in wages, the distinction between capital and income, and the theory of interest.

It is impossible in a short Note even to outline the richness and complexity of the analysis. For those who are interested in the marginal analysis and in capital theory the book is required reading, and the more general economist will not find much in it to cause him to revise his previous views. In an attempt to assess the importance of the work in the development of economic thought it is almost more

1. Friedrich and Vera Lutz, The Theory of Investment of the Firm. Princeton University Press, Princeton I951. X, 253 pages. 
important to notice what is not in it than what is in it. This is true of all books like this, which represent the culmination of a very special line of thought. The better the book the more important it is to raise the awkward and disagreeable question of whether the line of thought itself is a valid and useful one. When any line of thought is pursued to the end the question must be raised as to whether the end is a dead end; are all the significant questions answered, and if not, where are the roads that lead beyond the blind alley?

The very excellence and completeness of the work under review, therefore, makes the question all the more important as to the usefulness of the method employed. Does this elaborate analysis of maximization through time actually teach us very much about the real behavior of firms, and does it even give us a standard by which that behavior may be judged? The theory of profit maximization has rarely claimed to be a description of what firms actually do, and the present authors make no such claim. There is indeed a social-psychological theory of the firm, as a special case of the theory of organization, which discusses decisions in terms of the information which the executive receives, the dynamic patterns according to which information received by the executive becomes information or order sent out by him, the learning process by which past experience modifies the behavior reactions, the crisis-adjustment or stimulus-response patterns, the "feed back" by which a comparison of intentions with the information about results modifies policy, and so on. Economics has made very little contribution to this theory, nevertheless it is of vital importance in assessing the significance of the marginal analysis. Any claim on the part of the marginal analysis to be "realistic" - that is, to be a model which is helpful in understanding actual human behavior-can be defended only on the ground that behavior which diverges from that prescribed by the marginal analysis will result in two things: one, information regarding this divergence, and the other, action to lessen the divergence.

Unfortunately strong objections can be made to the marginal analysis on both these points. There is very little in the information system of a firm which informs the executive when he is not maximizing whatever he is supposed to be maximizing. This means that the maximum profit position, even supposing that the executive wanted to maximize profits, cannot be regarded as an equilibrium position in the proper sense, because if the entrepreneur is not informed about departures from the maximum there is obviously no force operating to bring him back to it if he diverges from it. It may properly be replied to this objection that gross departures from the maximum profit position do become obvious to the entrepreneur, and that hence there is at least a range of positions around the optimum which can be regarded as an equilibrium "range", in the sense that positions outside this range will result in information which will move the firm within the range again. It can also be said that the more skilled the entrepreneur becomes, the narrower will this equilibrium range be, and the closer will his behavior approximate to that required by the marginal analysis. These replies at least rescue the marginal analysis from those who would dispense with it altogether: it remains as an important limiting case of the more general theory of behavior.

There is, however, an objection to the principle of profit maximization which is perhaps even more destructive than the attacks on its "realism", and which is of 
particular importance in the applications of the maximization principle to the capital and time structure. This is the objection that even if the entrepreneur knew how to maximize profits there are many reasons why it would not be rational for him to do so. This argument, that is to say, denounces the principle of profit maximization as not merely unrealistic, but non-normative. There are two main reasons why a policy of profit maximization might not be ideal. The first is that it assumes that assets can be valued on a linear scale in terms of dollars, in the sense that a greater dollar value is always prefered to a smaller at the same time, and I suppose one should add, place. In fact however the structure and composition of assets may be highly significant in rational choice, and it may be impossible to range the possible clusters of assets on a simple linear scale. That is to say, there may be rational grounds for prefering one of two clusters of assets to another, even though the two have the same dollar value, because of some difference in composition--in say, liquidity, or flexibility, or even aesthetic qualities. The items of a balance sheet, that is to say, have something of the qualities of a gestalt which cannot be reduced to a linear scale. Indeed, the only circumstances under which it might reasonably be assumed that the entrepreneur was indifferent to the form of his asset cluster is the situation in which all assets (positive and negative) can be exchanged for all other assets at constant rates of transformation-that is, in which there are perfect markets for all assets. The moment imperfect markets for any asset (or liability) are introduced we can no longer assume that the entrepreneur is indifferent to the form of his asset cluster, and hence the principle of profit maximization itself falls to the ground, as the entrepreneur might, for instance, prefer a cluster of smaller dollar value, but in which the items were less exposed to imperfection in markets, to a cluster of greater dollar value in which the items were so exposed. The principle of profit maximization was first developed under the assumption of perfect markets, and it is still not generally realised how damaging to the principle itself is the extension of the marginal analysis to cover the case of the imperfect market.

The second objection to the profit maximization principle is closely related to the first, and is that it cannot adequately take account of the phenomena of uncertainty. The usual method of dealing with uncertainty in the theory of profit maximization is to replace the uncertain future magnitudes of revenues, outlays, or capital values with certainty equivalents derived from the assumed probability of the future magnitudes, and from the evaluation of risk itself on the part of the entrepreneur. That is to say we ask the entrepreneur, in effect: you hope for a dollar next year, but you are not quite sure of getting it: would eighty cents that you were absolutely sure of getting seem just as good to you as the dollar you are not sure about? If he says "yes", we simply substitute the eighty cents which is the "certainty equivalent" for the uncertain dollar, and proceed with our analysis as if nothing had happened and uncertainty were eliminated. Unfortunately, as Albert Hart has pointed out, this procedure completely begs the question. The whole problem is the effect of uncertainty itself on the behavior of the entrepreneur-what measures does he take to escape from it, to guard against it, and to protect himself from its consequences? It is no answer to this criticism, as Dr. and Mrs. Lutz seem to think (p. 183 ), to say that we can estimate the probabilities of 
the probabilities and still come out with certainty equivalents, because the presence of uncertainty modifies profoundly the form of the "rational" asset structure, distorting it away from "lucrativity" towards liquidity and flexibility. Here the principle of the minimax developed in the theory of games (making the best of the worst!) seems to be more applicable than the principle of maximization.

This basic defect in the principle of profit maximization itself seems to this writer to vitiate much of the most original part of the Lutz's work, where they apply the profit maximization principle to such problems as the cash balance and the financial structure. In brief, the Lutz's method is to identify (quite properly) the history of a firm with the history of its complete balance sheet, including cash balances, physical assets, debts and equities, and then to say that out of all possible histories that one will be chosen for which the present value of the "true" net worth (discounted net receipts) is a maximum. This procedure however rules out what is in practice one of the most interesting aspects of the theory of investment in the firm, which is the circumstances under which lucrativity (or net worth) is sacrificed for other things (security, control, respectability, and so on).

The defect of the method comes out especially clearly in the theory of the cash balance, and of liquid assets in general. We cannot explain as the Lutz's seem to try to do, the holding of cash balances in terms of the transactions motive and the speculative motive alone, though it is certainly true, as they point out, that these two motives cannot readily be separated. The "precautionary motive" - that is, the holding of assets in liquid form against unknown contingencies-is of great importance in explaining preferences for liquid assets, yet this cannot really be worked into any scheme of profit maximization except by the very unsatisfactory device of saying that long-run experience gives rise to certain rules of thumb which people believe are in the interests of long-run profit maximization. This device however merely obscures the real problem, which is that an increase in liquidity involves a sacrifice of expected profit in the interest of flexibility-flexibility being the ability to cope with the unexpected! This principle is particularly clear in the case of the theory of a bank, where the profit maximization principle has never been applied, and where the theorist has always relied on asset preference functions or parameters such as the reserve ratio to explain the bank's behavior.

All this does not necessarily mean that the principle of maximization must be abandoned. Even if we have to abandon the assumption that the firm maximizes any "objective" measure of profit, it still makes some kind of sense to assume that the firm maximizes "utility" - that is, that there is a preference function the topology of which can be discussed and which determines (or perhaps it would be better to say describes) which, out of the range of possible choices, is the "best". The assumption of a preference function in fact effects a great simplification in the theory of the firm, for we can throw all the future into the preference function and regard the action of the firm as taking place wholly in the present. The firm can then be thought of as manipulating its asset structure, through exchange or production, up to the point at which further transformations are not thought "worth while" that is, the point at which all marginal rates of transformation are equal to marginal rates of indifferent substitution. We can then discuss the formation of the preference function in terms of the effects of past experiences, and so develop 


\section{A NOTE ON THE THEORY OF INVESTMENT OF THE FIRM 8 I}

a true dynamics of the firm which sidesteps the whole difficult matter of explicit formulation of expectations.

I have been critical of the foundations on which the Lutz's work has been raised. My criticism of the foundations in no way implies criticism of the elegance and completeness of the structure. I do believe- - to vary the metaphor-that the road which they have taken is in fact a blind alley. It is a great service to the profession however to explore even a blind alley to its fullest extent, for we can never be sure there is no way out of it until it has been fully explored. For this reason economists must be grateful to the Lutz's for the careful and thorough way in which they have followed their task through.

The University of Michigan Ann Arbor, Michigan (U.S.A.)

KENNETH E. Boulding 
